\title{
Simultaneous Use of Herbal Medicines and Antihypertensive Drugs Among Hypertensive Patients in the Community: A Review
}

This article was published in the following Dove Press journal: Journal of Multidisciplinary Healthcare

\author{
Nur Azizah iD ${ }^{1,2}$ \\ Eli Halimah (iD) 1,3 \\ Irma Melyani Puspitasari (iD) 1,3 \\ Aliya Nur Hasanah (iD ${ }^{4}$ \\ 'Department of Pharmacology and \\ Clinical Pharmacy, Faculty of Pharmacy, \\ Universitas Padjadjaran, Sumedang, West \\ Java, 45363, Indonesia; ${ }^{2}$ Muhammadiyah \\ Kuningan Institute of Health Science, \\ Cigugur-Kuningan, West Java, 4555I, \\ Indonesia; ${ }^{3}$ Center of Excellence in \\ Higher Education for Pharmaceutical \\ Care Innovation, Universitas Padjadjaran, \\ Sumedang, West Java, 45363, Indonesia; \\ ${ }^{4}$ Department of Pharmaceutical Analysis \\ and Medicinal Chemistry, Faculty of \\ Pharmacy, Universitas Padjadjaran, \\ Sumedang, West Java, 45363, Indonesia
}

\begin{abstract}
In various countries, approximately $80 \%$ of patients use herbal medicine, both in single form or in combination with antihypertensive drugs, for the treatment of hypertension. Therefore, this research summarized studies on the simultaneous use of herbal medicines and antihypertensive drugs among hypertensive patients in the community. A literature search was conducted on PubMed in April 2020, and the following keywords were used: "herbal medicines" and "antihypertensive patients." In total, 15 of 263 articles were found to be eligible in the initial research. Results showed that studies were performed in different countries worldwide including America and those in Europe, Asia, and Africa between 1960 and 2020. The factors associated with the use of herbal medicines and antihypertensive drugs were age, gender, education level, income, and residence. Herbal medicines and antihypertensive drugs are simultaneously utilized primarily due to their safety and high efficacy. Herbal medicine is frequently recommended by friends or colleagues, herbalists, advertisements, and health workers. Garlic is the most common herbal medicine used along with antihypertensive drugs. The side effects of combination therapy with herbal medicines and prescription drugs for the management of antihypertension include shortness of breath and cough, ulcers, diarrhea, knee cramps, and abdominal discomfort. The lack of communication between patients and health care workers could cause an increase in the simultaneous use of herbal medicines and antihypertensive drugs. Therefore, effective communication among health care workers and appropriate care are important in preventing the side effects and other risks of combined therapy.
\end{abstract}

Keywords: combination use, herbal medicine, antihypertensive drug, hypertensive patients

\section{Introduction}

Hypertension, or high blood pressure, is one of the common health problems worldwide. Its prevalence is high, and it is considered a major risk factor for cardiovascular diseases and other complications. ${ }^{1}$ According to the World Health Organization, high blood pressure occurs when two consecutive measurements remain $\geq 140 / 90 \mathrm{mmHg}$. Approximately $30 \%$ of men and $50 \%$ of women aged $65-75$ years present with hypertension. Moreover, 1.56 billion people are hypertensive worldwide. This value indicates a $60 \%$ increase in the prevalence of hypertension. ${ }^{2}$

Currently, approximately $75 \%-80 \%$ of the world's population, including hypertensive patients, use herbal medicines due to the receptive nature of the body toward herbs, and the low incidence of side effects. ${ }^{3}$ Several ethnobotany studies conducted in various parts of the world have shown that hundreds of plants can lower blood pressure.
Correspondence: Eli Halimah Department of Pharmacology and Clinical Pharmacy, Faculty of Pharmacy, Universitas Padjadjaran, Jalan Bandung Sumedang KM 21 , Jatinangor Sumedang, 45363, Indonesia Tel +62 2284288888 Ext 35I0

Email eli.halimah@unpad.ac.id
Journal of Multidisciplinary Healthcare 2021:14 259-270 
Therefore, they are used in the treatment of hypertension. ${ }^{4}$ Approximately $47.5 \%$ of hypertensive patients simultaneously use herbal medicines and antihypertensive drugs. ${ }^{5}$ In a study conducted in Jamaica, $79.5 \%$ of these patients also utilize this drug combination. ${ }^{6}$

Another article reported that 78 (19.5\%) of 400 hypertensive patients simultaneously used herbal complementary therapy and conventional medicine. ${ }^{7}$ The increasing use of this drug combination and its side effects caused a global health problem that should be addressed. Therefore, the safety of herbal medicine should be assessed to minimize unexpected risks. ${ }^{6}$

A systemic review of the prevalence of traditional drugs, time and effect of use, and reasons for use among hypertensive patients have been performed particularly in Sub-Saharan Africa. ${ }^{5}$ In the study of Agbabiaka et al, herbal medicines and prescription drugs were simultaneously used. However, this review did not focus on hypertensive patients. ${ }^{8}$ Meanwhile, Rahmawati and Bajorek conducted a study on self-medication using over-the-counter drugs and complementary alternative medicines among hypertensive patients. However, the use of herbal medicines was not specified. ${ }^{9}$ Furthermore, no specific review was performed on patient criteria, sociodemographic characteristics, reasons for the simultaneous use of herbal medicines and antihypertension drugs, herbal names, drugs used, and perceived side effects of combination therapy. Therefore, this article aimed to discuss the simultaneous use of herbal medicines and antihypertensive drugs among hypertensive patients in the community. Moreover, the sociodemographic characteristics and factors correlated with this combination therapy, considered as evidence-based information, and its unexpected risks were discussed.

\section{Literature Search}

A literature search was conducted on PubMed in April 2020 using keywords such as "herbal medicines" and "hypertensive patients." The detailed keywords were as follows: ("plants, medicinal"[MeSH Terms] OR "plants"[All Fields]) AND ("medicinal"[All Fields] OR "medicinal plants"[All Fields] OR "herbal"'[All Fields]) AND ("medicines"[All Fields] OR "herbal medicines"[All Fields]) AND ("hypertense"[All Fields] OR "hypertension"[MeSH Terms] OR "hyper tension"[All Fields] OR "hypertension s"[All Fields] OR "hypertensions"[All Fields] OR "hypertensive"[All Fields] OR "hypertensive s"[All Fields] OR "hypertensives"[All Fields]) AND ("patients"[All Fields] OR "patients"[MeSH Terms] OR "patients"[All Fields] OR "patient”[All Fields]
OR "patients s"[All Fields]). This study included research studies, articles written in English, and survey research on the combined use of herbal medicines and prescribed drugs among hypertensive patients. The flow chart of the literature is depicted in Figure 1.

\section{Use of Herbal Medicines Among Hypertensive Patients}

Table 1 shows the summary of 15 cross-sectional studies on the use of herbal medicines among hypertensive patients. These studies had been carried out in various countries including America and those in Europe, Asia, and Africa between 1960 and 2020. In total, 7302 hypertensive patients participated in these studies. Furthermore, 3714 hypertensive patients used herbal medicines, and 262 simultaneously used herbal medicines and antihypertensive drugs. Fifteen research articles discussed the proportion of patients who used a combination of drugs, and six articles showed the number of hypertensive patients who received combination therapy.

\section{Sociodemographic Characteristics of Hypertensive Patients Who Simultaneously Used Herbal Medicines and Antihypertensive Drugs}

Table 2 depicts the sociodemographic characteristics of hypertensive patients who simultaneously used herbal

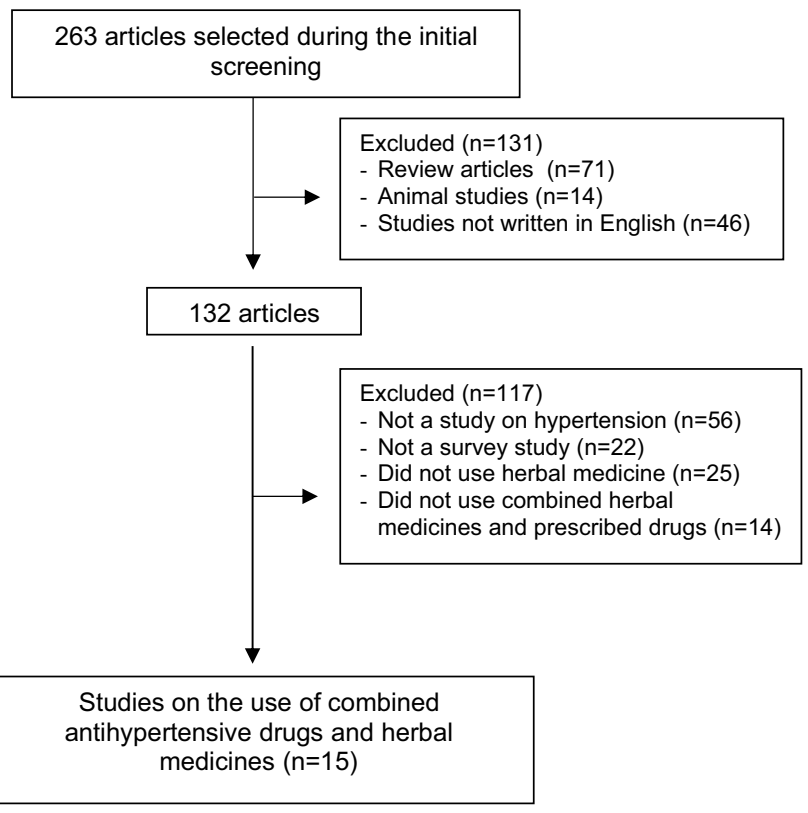

Figure I Flowchart of literature search. 


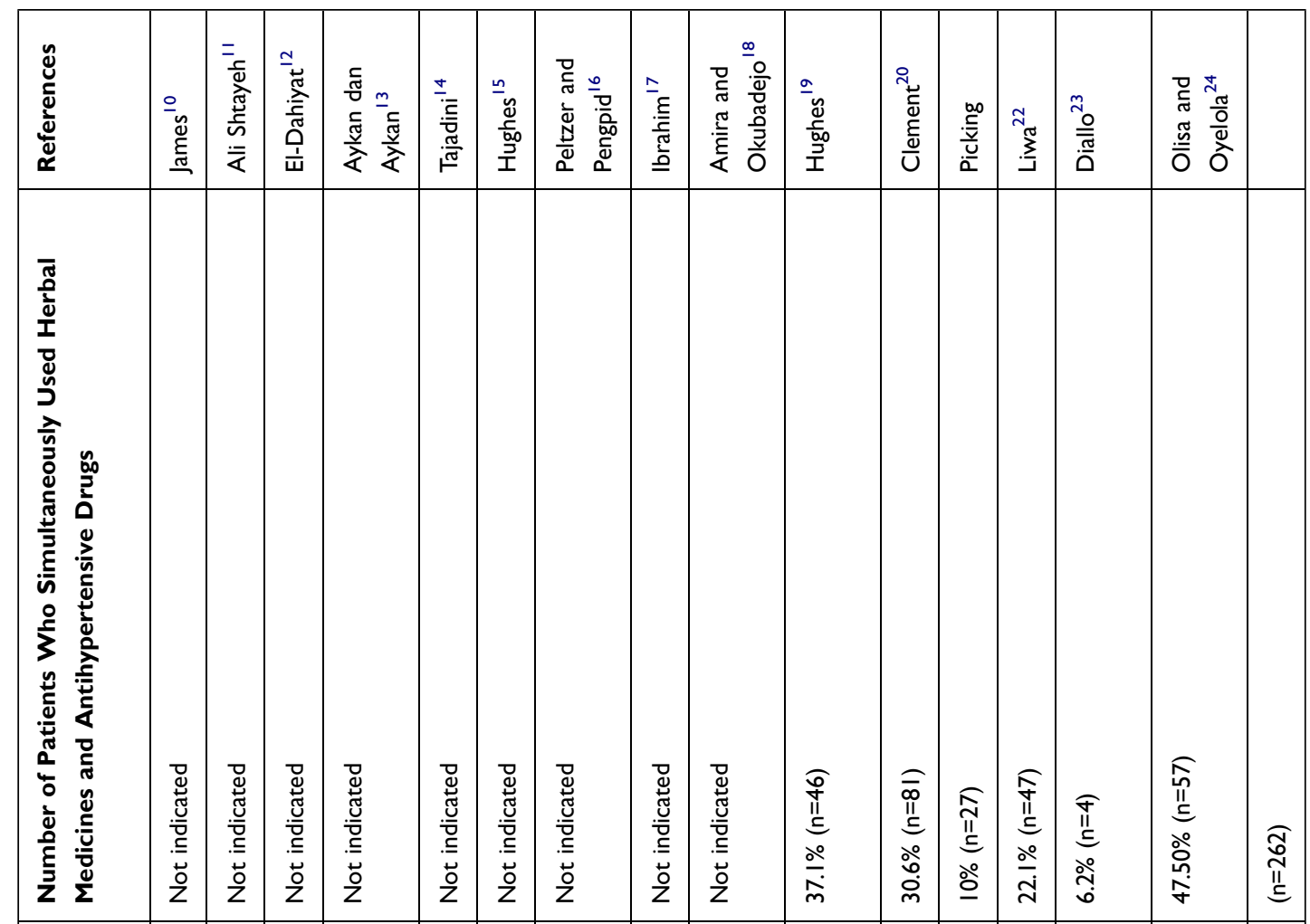

\begin{tabular}{|c|c|c|c|c|c|c|c|c|c|c|c|c|c|c|c|c|c|}
\hline 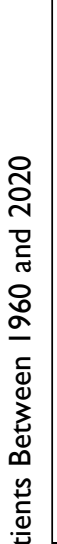 & 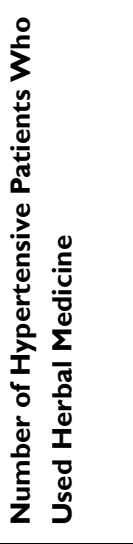 & 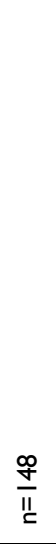 & 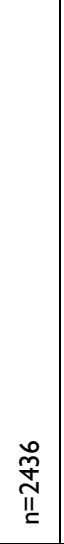 & $\underset{\tilde{N}}{\stackrel{\pi}{\leftarrow}}$ & $\stackrel{\infty}{\frac{\infty}{11}}$ & $\frac{a}{11}$ & $\underset{\pi}{\infty}$ & 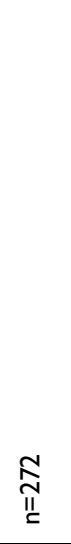 & $\overline{\bar{I}}$ & $\stackrel{\stackrel{\sim}{\dddot{n}}}{\underline{c}}$ & $\stackrel{\text { II }}{\text { II }}$ & $\stackrel{n}{\stackrel{n}{\dddot{n}}}$ & $\underset{I}{\tilde{H}}$ & $\stackrel{\text { ò }}{I}$ & $\stackrel{\text { I0 }}{\text { II }}$ & $\stackrel{\text { II }}{11}$ & $\begin{array}{l}\frac{\sigma}{\sqrt{n}} \\
m \\
\text { II }\end{array}$ \\
\hline 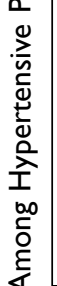 & 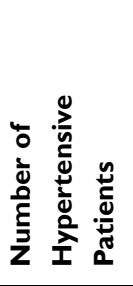 & $\underset{\stackrel{O}{0}}{\mathbb{1}}$ & $\begin{array}{l}\bar{\alpha} \\
\stackrel{0}{I I}\end{array}$ & $\stackrel{\tilde{N}}{\underline{I 1}}$ & 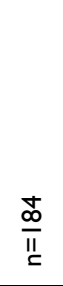 & $\stackrel{\text { II }}{\text { II }}$ & $\stackrel{\stackrel{m}{m}}{\frac{m}{11}}$ & $\begin{array}{l}\infty \\
\infty \\
\infty \\
\Perp\end{array}$ & $\underset{\substack{\text { II } \\
\text { II }}}{ }$ & 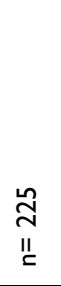 & $\stackrel{ \pm}{\frac{ \pm}{I I}}$ & $\stackrel{+}{\Perp}$ & $\underset{\text { II }}{\text { II }}$ & $\stackrel{m}{\pi}$ & $\frac{\mathcal{F}}{\underline{I}}$ & $\stackrel{\infty}{\infty}$ & 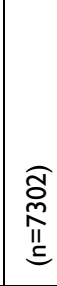 \\
\hline 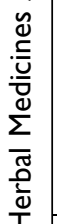 & 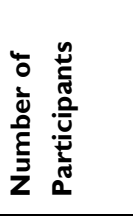 & $\underset{\stackrel{O}{0}}{\mathbb{1}}$ & 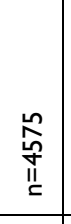 & $\stackrel{\substack{\tilde{m} \\
\stackrel{11}{L}}}{ }$ & 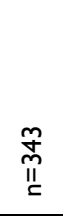 & $\frac{N}{\text { II }}$ & $\frac{\stackrel{m}{m}}{11}$ & 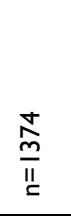 & $\stackrel{\text { II }}{\Perp}$ & $\stackrel{\stackrel{\sim}{\pi}}{\dddot{\pi}}$ & 冞 & 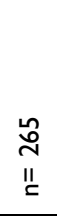 & $\underset{\substack{\text { II } \\
\Sigma}}{2}$ & $\stackrel{m}{\pi}$ & $\frac{0}{m}$ & $\begin{array}{l}\stackrel{\circ}{\not ̊} \\
\text { "I } \\
=\end{array}$ & 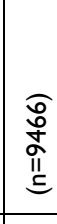 \\
\hline 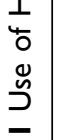 & 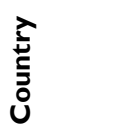 & 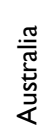 & 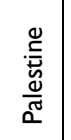 & $\begin{array}{l}\frac{5}{5} \\
\text { क्ञ } \\
\text { 흐 }\end{array}$ & 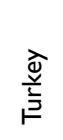 & 胥 & 苋 & 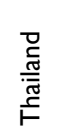 & $\underline{\mathscr{\mathscr { F }}}$ & 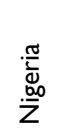 & 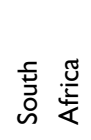 & 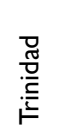 & 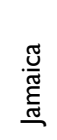 & 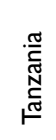 & 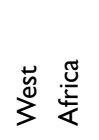 & 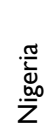 & \\
\hline & $\dot{\mathbf{z}}$ & - & N & $m$ & $\sigma$ & in & 0 & $\wedge$ & $\infty$ & $\sigma$ & 으 & $=$ & $\simeq$ & $\underline{m}$ & \pm & $\underline{\underline{n}}$ & \\
\hline
\end{tabular}




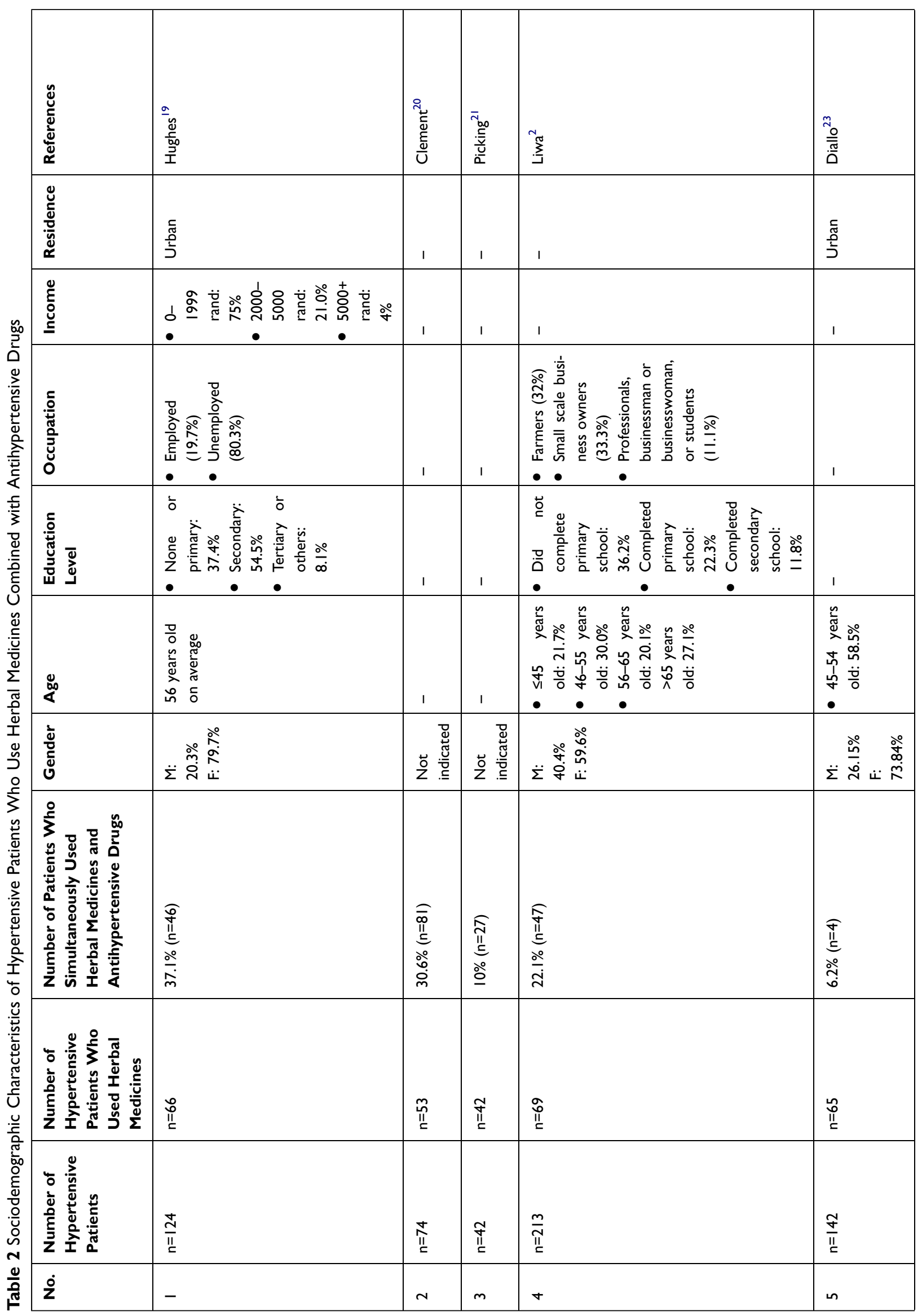




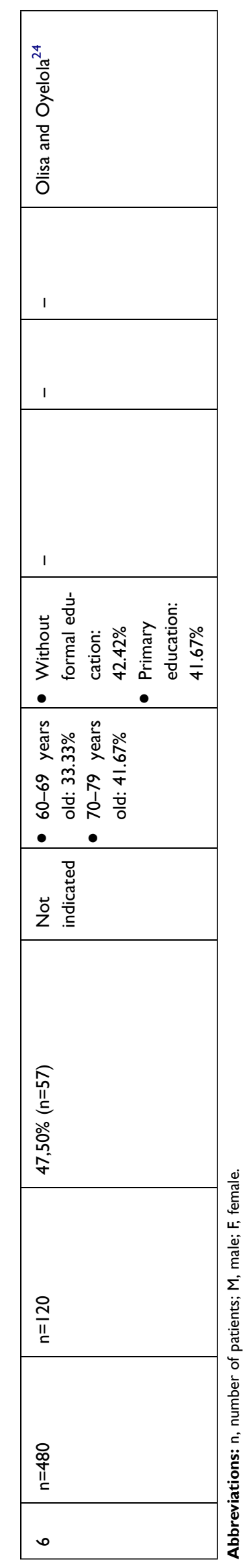

medicines and antihypertensive drugs in six articles. These characteristics include gender, age, education level, occupation, income, and residence.

In total, three articles showed that the number of female patients using combined herbal medicines and antihypertensive drugs was higher than that of male patients. ${ }^{19,22,23}$ Two studies in Africa revealed that the number of female hypertensive patients who used herbal medicines for treating hypertension was higher than that of male hypertensive patients $(79.7 \%$ and $73.84 \%$, respectively). ${ }^{19,23}$ In Tanzania, the number of female patients (59.6\%) who simultaneously used herbal medicines and antihypertensive drugs for the management of hypertension was higher than that of male patients $(40.4 \%) .^{22}$ This finding was in accordance with that of a research conducted in Turkey that showed that the number of female patients (84.1\%) was higher than that of male patients $(15.9 \%) .{ }^{25}$ Clement et al conducted a study in Trinidad and results showed that the number of female patients $(73.20 \%)$ who used herbal medicine for the treatment of hypertension was higher than that of male patients $(26.8 \%))^{20}$ Therefore, based on the gender criteria of the three articles in this review, female patients were the most common users of combined herbal medicines and antihypertensive drugs.

In total, four articles discussed the age of hypertensive patients who used herbal medicines. Studies from Diallo revealed that approximately $58.5 \%$ of herbal users in Guinea City, Africa, were aged 45-55 years. ${ }^{23}$ Meanwhile, Liwa et al showed that approximately $27.1 \%$ of users in Tanzania were aged $>65$ years. ${ }^{22}$ Olisa et al performed a study in Nigeria. Results showed that approximately $41.67 \%$ of herbal users were aged $70-79$ years. ${ }^{24}$ Furthermore, a research conducted in South Africa showed that the users of herbal medicine were aged 49-64 years. ${ }^{19}$ On the basis of these studies, the use of combined herbal medications and hypertensive drugs was found to be correlated with age.

Furthermore, three articles reported on the educational levels of herbal users. Hughes et al revealed that approximately $54.5 \%$ of participants had secondary education. ${ }^{19}$ Liwa et al showed that $36.2 \%$ of patients did not graduate from elementary school; $22.3 \%$ and $11.1 \%$ completed primary and secondary schools, respectively; and $42.42 \%$ did not obtain any education. ${ }^{22}$ Meanwhile, Olisa and Oyelola revealed that $42.42 \%$ of herbal users had no formal education. ${ }^{24}$ This result was in accordance with that of the study of Aykan that showed that $57.1 \%$ of people in 
Turkey had a low educational level. ${ }^{13}$ However, this result was different from that of the study of Soner, which showed that $48.8 \%$ of herbal users were women with high educational levels and family incomes. ${ }^{26}$

In addition, the simultaneous use of herbal medicines and antihypertensive drugs was found to be correlated with occupational status, as observed in the two articles. ${ }^{19,22}$ Hughes et al showed that the utilization of combined herbal medicines and prescribed drugs was commonly observed in unemployed patients $(80.3 \%)$, and approximately $19.7 \%$ of patients were workers or employees. ${ }^{19}$ Meanwhile, Liwa et al revealed that combination treatment was frequently observed in patients with small businesses (33.3\%), farmers $(32.1 \%)$, and professionals and entrepreneurs $(11.1 \%){ }^{22}$

In terms of residence, two articles showed that research was conducted in an urban area in West and South Africa. ${ }^{19,23}$ However, Picking et al revealed that the use of herbal medicines was more commonly observed in hypertensive patients $(21.8 \%)$ living in rural areas than in those (42.42\%) living in urban areas. ${ }^{21}$

\section{Factors Correlated with the Simultaneous Use of Herbal Medicines and Antihypertensive Drugs}

Table 3 presents the factors correlated with the simultaneous use of herbal medicines and antihypertensive drugs. These include the number of patients, reasons for use, informants, names or types of herbal medicines, methods of obtaining and using these medicines, type/name of hypertension drugs, and perceived side effects. Of the 15 research articles, only 6 discussed these factors. ${ }^{19-24}$

\section{Reasons for the Simultaneous Use of Herbal Medicines and Antihypertensive Drugs}

The reasons for using combined herbal medicines and antihypertensive drugs varied in $11.1-23.08 \%$ of patients. That is, conventional medicine was more expensive than herbal medicine. ${ }^{19,21,24}$ Approximately $31.9 \%$ of patients believed that traditional medicine was effective on the basis of their social and cultural beliefs (20.19-33.3\%) and family history $(48.8 \%))^{5,19,24}$ Tajadini showed that herbal medicines were used as adjunctive therapy for lowering blood pressure. ${ }^{14}$ Meanwhile, approximately
$8-70.4 \%$ of patients claimed that herbal medicines were highly effective and did not cause problems when used concurrently with antihypertensive drugs. ${ }^{20-22}$ This result was similar to that of the study of Delgoda et al that showed that the reason for the concurrent use of herbal medicines and prescribed drugs was attributed to hereditary beliefs. ${ }^{6}$

\section{Individuals Who Recommend the Simultaneous Use of Herbal Medicines and Antihypertensive Drugs}

Hughes et al revealed that hypertensive patients used herbal remedies based on recommendations by family (58.7\%), friends or colleagues (18.1\%), advertisements (2.6\%), and herbalists (6.9\%). Meanwhile, only $1.7 \%$ of participants used herbal medicines according to the recommendation of health care workers. ${ }^{19}$ Liwa et al showed that approximately $1.5 \%$ of recommendations were from herbalists. ${ }^{5}$ Olisa and Oyelola explained that the use of herbal medicines among hypertensive patients was recommended by sales representatives. ${ }^{24}$ Furthermore, in Ethiopia, it was widely recommended by herbalists to $37.8 \%$ of users who were not satisfied with the conventional therapy. ${ }^{27}$ Some studies showed that the increasing use of herbal medicine for the treatment of hypertension was attributed to the assumption that herbal medicines do not have several side effects as compared with prescription drugs or chemicals. Moreover, the use of herbal medicine was a hereditary culture. ${ }^{19,22,23}$ Erku showed that $70.2 \%$ of patients did not inform health workers about the use of herbal medicine, and they did have sufficient knowledge regarding such therapy. ${ }^{27}$ They refused to inform health workers, believing that it was unnecessary $(53.6 \%)$, and some were afraid that their physicians would be angry or upset (7.1\%). Moreover, approximately $28.6 \%$ were not assessed regarding the use of this therapy. ${ }^{28} \mathrm{~A}$ research conducted in Ghana showed that approximately $70 \%$ of hypertensive patients who use herbal medicine did not inform health workers due to fear and lack of information regarding herbal treatments. ${ }^{7}$

\section{Types of Herbal Medicines and Antihypertensive Drugs}

Garlic has been used as a herbal medicine for hypertension and was used in four studies. ${ }^{20-22,24}$ According to the research conducted by Liwa et al, $83.2 \%$ of patients were not familiar with the name of the herbal medicine. 


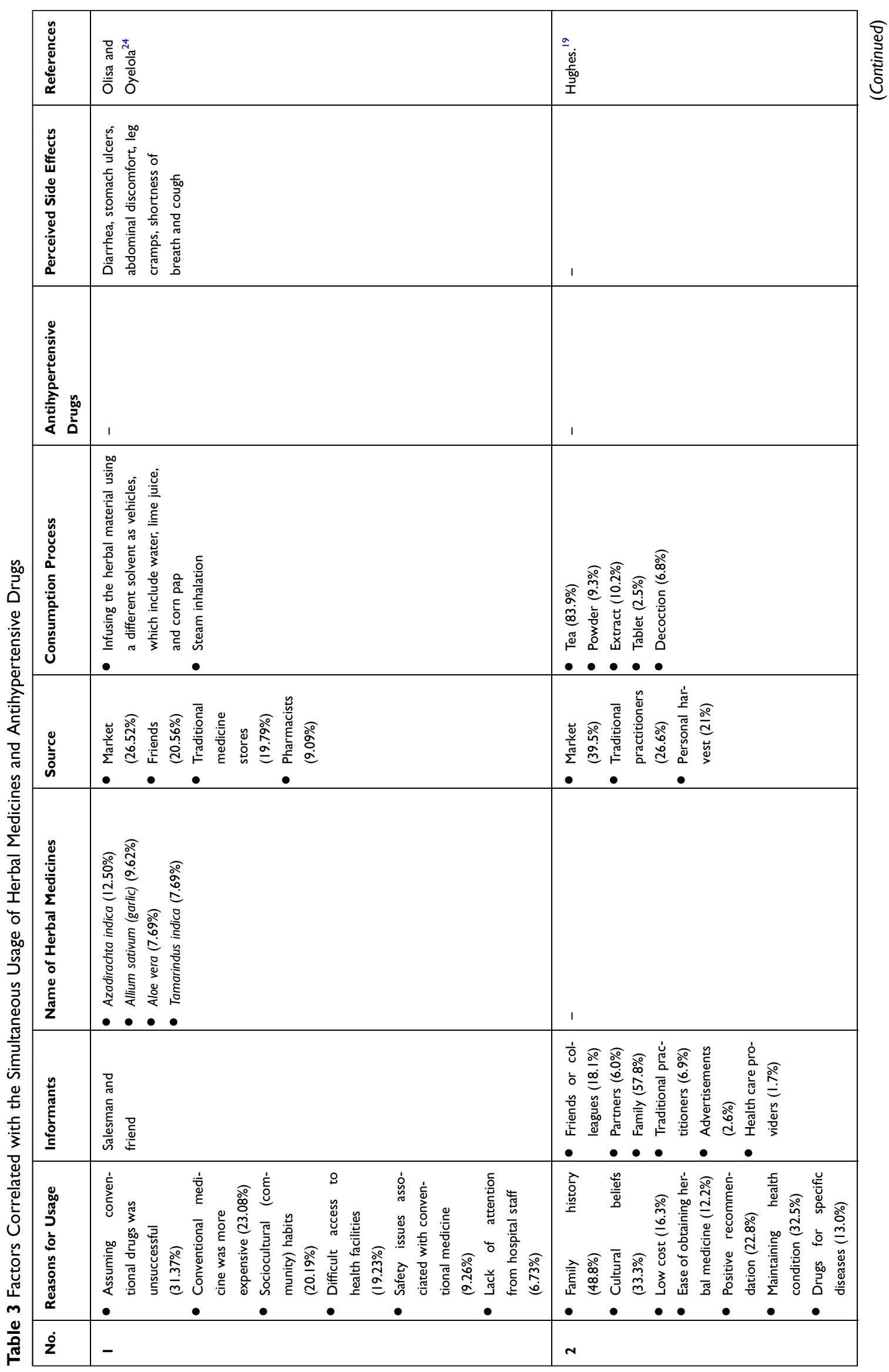




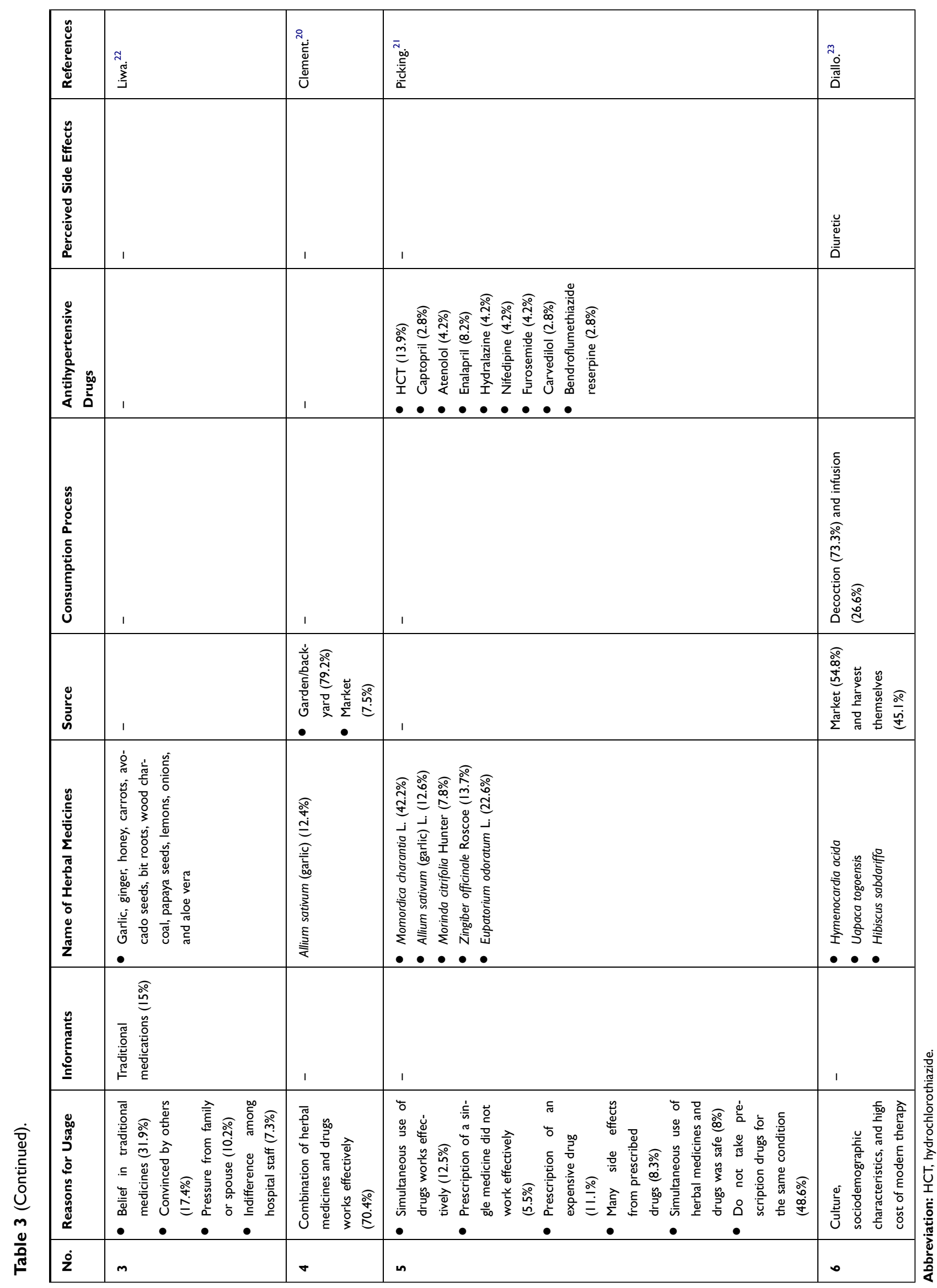


Meanwhile, $16 \%$ were cognizant, and $13.0 \%$ used more than one herbal ingredient, one of which was garlic $(29.72 \%){ }^{22}$ This study showed that in addition to Azadirachta indica, garlic $(9.62 \%)$ is also a herbal medicine used by hypertensive patients in Nigeria. ${ }^{24}$ Meanwhile, the research conducted in Trinidad showed that garlic was the most widely used herb for the management of hypertension, and approximately $48.3 \%$ of patients used combined garlic and antihypertensive drugs. ${ }^{20}$ These results were in accordance with those of the study of Aykan. This research showed that $71.2 \%$ of patients with cardiovascular diseases in Turkey used garlic, and $51.9 \%$ often took both garlic and antihypertensive drugs (beta $[\beta]$-blocker). ${ }^{13}$

Garlic had several benefits in the treatment of cardiovascular diseases. These include lowering blood pressure, and the bioactive component of garlic had an antioxidant effect that can induce smooth muscle cell relaxation and vasodilation and lower blood pressure. ${ }^{22,29}$ Picking et al showed that garlic is often used simultaneously with an antihypertensive drug, particularly hydrochlorothiazide (HCT), among hypertensive patients in Jamaica. Moreover, it is utilized simultaneously with captopril, hydralazine, nifedipine, and reserpine, in addition to HCT and $\beta$-blockers, and pear and breadfruit leaves. ${ }^{21}$

In addition to garlic, other types of herbal medicine are used. These include Aloe vera (7.69\%), Tamarindus indica (7.69\%), and Azadirachta indica (12.50\%). ${ }^{24}$ Some herbs used by hypertensive patients were Momordica charantia L. (42.2\%), Morinda citrifolia Hunter (7.8\%), Zingiber officinale Roscoe (13.75\%), and Eupatorium odoratum L (22.6\%). ${ }^{21}$ Meanwhile, hypertensive patients in the urban area of Guinean in Belgium often use Hymenocardia acida leaves, Uapaca togoensis bark, and Hibiscus sabdariffa. ${ }^{23}$

The antihypertensive drugs commonly used in combination with herbal medicines include hydrochlorothiazide (13.9\%), enalapril $(8.3 \%)$, atenolol $(4.2 \%)$, nifedipine (4.2\%), hydralazine (4.2\%), and captopril $(2.8 \%){ }^{21}$ Meanwhile, on the basis of research conducted in Turkey, the antihypertensive drugs often used in combination with herbal medicines include angiotensin-converting enzyme inhibitors $(23.9 \%)$, angiotensin II receptor blockers $(14.9 \%), \beta$-blockers $(51.9 \%)$, and calcium channel blockers $(15.7 \%){ }^{13}$

\section{Source and Use of Herbal Medicine}

The various methods used for obtaining herbal ingredients include independent planting; buying from shops, markets, and supermarkets; and prescription from healthcare providers. However, most patients obtained herbal medicine from market purchases. Clement et al showed that herbal users in Trinidad obtained herbal medicine from their gardens or backyards $(79.2 \%)$ and from markets $(7.5 \%){ }^{20}$ Meanwhile, a research conducted in Nigeria revealed that patients obtained herbal medicine from the market $(26.52 \%)$, friends $(20.56 \%)$, traditional medication stores $(19.79 \%)$ and pharmacists $(9.09 \%){ }^{24}$ Approximately $54.8 \%$ of hypertensive patients in Guinean, Belgium, purchased herbal medicines from the market, and approximately $45.1 \%$ of patients harvested herbal medicines themselves. ${ }^{23}$ Meanwhile, hypertensive patients in an urban South African community obtained herbal medicines from the market $(39.5 \%)$, traditional practitioners $(26.6 \%)$, and personal harvests $(21 \%) .{ }^{19}$ Finally, herbal ingredients were processed by infusing herbal materials using different solvents as vehicles, which include water, lime juice, and corn pap. ${ }^{24}$ Herbal medicine is prepared as a decoction $(73.3 \%)$ or an infusion (26.6\%) using water. ${ }^{23}$ Hypertensive patients take herbal medicines in the form of tea $(83.9 \%)$, powder $(9.3 \%)$, and extract $(10.2 \%) .{ }^{19}$

\section{Herbal Medicine-Antihypertensive Drug Interaction}

Herbal-drug interactions become clinically significant when considerable changes occur in the pharmacokinetic parameters of drugs that are taken with herbal medicine. The interactions often occur as a result of changes in drug metabolic activity and protein transport, especially cytochrome P450 and P-glycoprotein isoenzymes, which can be increased or inhibited by synthetic or herbal drugs. ${ }^{30,31}$ Pharmacodynamic interactions can be additive (or synergistic) when herbal medicine potentiates the pharmacological or toxicological effects of synthetic drugs; for example, interactions between warfarin and the antiplatelet herbal medicine may enhance the anticoagulant effect of warfarin. $^{32}$

Some examples of interactions between herbal medicine and antihypertensive drugs are as follows: amlodipine with ginkgo leaf tablets increased the Tmax, Cmax, $\mathrm{t}_{1 / 2}$, and AUC of amlodipine, so ginkgo leaf tablets were suspected to change the pharmacokinetic parameters of amlodipine through modulation of the CYP3A4 enzyme metabolism. ${ }^{33}$ Simultaneous use of Rosella and HCT can increase urine volume, decrease urine $\mathrm{pH}$, and 
concentrations of sodium, bicarbonate, and chloride ions. In addition, the use of rosella with HCT can increase and extend the Cmax, AUC, and volume distribution of HCT. $^{34}$ The use of propanolol and Eurycoma longifolia simultaneously can affect the propanolol absorption process, whereas Eurycoma longifolia induces the transport of P-glycoprotein (P-gp) waste, thereby increasing the extrusion of propanolol from epithelial cells into the intestinal lumen. ${ }^{35}$ Meanwhile, the effects of breadfruit leaf and peperomia pellucida extracts on the activity of the CYP3A4 and CYP2D6 enzymes show that the two extracts do not cause significant side effects when consumed together with other medications that depend on CYP3A4 and CYP2D6 metabolisms. ${ }^{36,37}$

In addition, interactions that affect drug absorption may involve active transporters located in the intestinal membrane. ${ }^{38}$ Intestinal metabolism plays an important role in drug bioavailability and clinical efficacy. Induction of this metabolic enzyme by xenobiotics can decrease the amount of drug absorbed, which leads to a loss of clinical efficacy. On the other hand, inhibition of intestinal metabolism increases the amount of drug available, increasing the possibility of toxicity and adverse drug reactions. ${ }^{39}$ For example, when grapefruit juice is used simultaneously with felodipine or 1.4-dihydropyridine calcium antagonists, it can inhibit intestinal CYP3A4 and increase felodipine bioavailability, and inhibition of intestinal metabolism can increase the amount of drugs in the body, which can lead to toxicity and adverse drug reactions. ${ }^{39,40}$ Another study suggested simultaneous use of peppermint oil capsules with felodipine can increase the bioavailability of felodipine and cause side effects such as headache, dizziness, and flushing. ${ }^{41}$ Furthermore, the use of antihypertensive drugs can also have an antagonistic effect when used together with herbs with antihypertensive activity, causing vasoconstriction, fluid retention, and potential vasodilation. ${ }^{42}$

\section{Perceived Side Effects}

The simultaneous use of herbal medicines and antihypertensive drugs caused unexpected side effects. As shown in the study of Aykan, approximately $6.7 \%$ of patients in Turkey experienced side effects. ${ }^{13}$ The research conducted by Olisa and Oyelola revealed that in Nigeria, $21.04 \%$ of patients presented with side effects such as ulcers $(3.51 \%)$, knee cramps $(3.51 \%)$, shortness of breath and cough $(3.51 \%)$, skin reactions $(3.51 \%)$, erectile dysfunction $(1.75 \%)$, diarrhea $(1.75 \%)$, gastroenteritis $(1.75 \%)$, and abdominal discomfort $(1.75 \%){ }^{24}$ The patient believes that these side effects are due to the use of herbal medicine; these side effects were attenuated after the use of herbal medicine was stopped. ${ }^{24}$ This result was quite similar to that of the research of Clement et al that showed that $6 \%$ of hypertensive patients using combination therapy in Trinidad experienced side effects. ${ }^{20}$ In addition, other studies showed that this combination therapy increased the risk of diuresis, hypotension, and hypokalemia. ${ }^{43}$

According to the number of users and its side effects, special attention from health workers was required to address these issues. Meanwhile, the lack of communication between patients and doctors or other health care workers was the most common obstacle observed in all studies on herbal usage, both in singular and combined form.

\section{Conclusion}

Herbal medicines and antihypertensive drugs were simultaneously used by 262 of 7302 hypertensive participants in this study. The frequent usage was found to be influenced by the sociodemographic characteristics, such as gender, age, education level, occupation, and residence. Herbal medicines and antihypertensive drugs were primarily used due to their safety and high efficacy. In this case, garlic was the most commonly used herbal medicine. Meanwhile, $\beta$-blocker is a class of antihypertensive drug often used simultaneously with herbal medicines. The side effects of combined herbal medicines and prescription drugs among hypertensive patients included shortness of breath and cough, ulcers, diarrhea, knee cramps, and abdominal discomfort. The factors associated with the increased usage of combined herbal medicines and drugs included perceived fear and lack of initiative from doctors and health workers. Effective communication among health care workers and appropriate care were required to prevent the side effects and other risks of combination therapy.

\section{Disclosure}

The authors report no conflicts of interest in this work.

\section{References}

1. Singh S, Shankar R, Singh GP. Prevalence and associated risk factors of hypertension: a cross-sectional study in urban varanasi. Int $J$ Hypertens. 2017;2017:5491838. doi:10.1155/2017/5491838

2. Tsabang N, Yedjou CG, Tchounwou PB. Phytotherapy of high blood pressure in three phytogeographic regions of cameroon. Pharm Anal Acta. 2017;08:01. doi:10.4172/2153-2435.1000530 
3. Tabassum N, Ahmad F. Role of natural herbs in the treatment of hypertension. Pharmacogn Rev. 2011;5(9):30. doi:10.4103/09737847.79097

4. Landazuri P, Chamorro NL, Cortes BR. Medicinal plants used in the management hypertension. J Anal Pharm Res. 2017;5(2):5-7. doi:10.15406/japlr.2017.05.00134

5. Liwa AC, Smart LR, Frumkin A, Epstein H-AB, Fitzgerald DW, Peck RN. Traditional herbal medicine use among hypertensive patients in sub-saharan africa: a systematic review. Curr Hypertens Rep. 2014;16(6):437. doi:10.1007/s11906-014-0437-9

6. Delgoda R, Younger N, Barrett C, Braithwaite J, Davis D. The prevalence of herbs use in conjunction with conventional medicines in Jamaica. Complement Ther Med. 2010;18(1):13-20. doi:10.1016/j. ctim.2010.01.002

7. Kretchy IA, Owusu-Daaku F, Danquah S. Patterns and determinants of the use of complementary and alternative medicine: a cross-sectional study of hypertensive patients in Ghana. BMC Complement Altern Med. 2014;14(1):44. doi:10.1186/1472-6882-14-44

8. Agbabiaka TB, Wider B, Watson LK, Goodman C. Concurrent use of prescription drugs and herbal medicinal products in older adults: a systematic review. Drugs Aging. 2017;34(12):891-905. doi:10.1007/ s40266-017-0501-7

9. Rahmawati R, Bajorek BV. Self-medication among people living with hypertension: a review. Fam Pract. 2017;34(2):147-153. doi:10.1093/fampra/cmw137

10. James PB, Kamara H, Bah AJ, Steel A, Wardle J. Herbal medicine use among hypertensive patients attending public and private health facilities in Freetown Sierra Leone. Complement Ther Clin Pract. 2018;31:7-15. doi:10.1016/j.ctcp.2018.01.001

11. Ali-Shtayeh MS, Jamous RM, Jamous RM, Salameh NMY. Complementary and alternative medicine (CAM) use among hypertensive patients in Palestine. Complement Ther Clin Pract. 2013;19 (4):256-263. doi:10.1016/j.ctcp.2013.09.001

12. El-Dahiyat F, Rashrash M, Abuhamdah S, Abu Farha R, Babar Z-UD. Herbal medicines: a cross-sectional study to evaluate the prevalence and predictors of use among Jordanian adults. J Pharm Policy Pract. 2020;13(2):1-9. doi:10.1186/s40545-019-0200-3

13. Aykan DA, Aykan AC. Factors associated with the concomitant use of cardiovascular drugs and dietary herbal products: a cross-sectional study. J Cardiovasc Pharmacol Ther. 2019;24(2):146-152. doi:10.1177/1074248418794938

14. Tajadini H, Divsalar K, Mehrabani M, et al. The frequency of using herbal medicines among patients with hypertension in Kerman, Iran, 2012-2013. J Evidence-Based Complement Altern Med. 2015;20 (3):199-202. doi:10.1177/2156587215573141

15. Hughes GD, Aboyade OM, Clark BL, Puoane TR. The prevalence of traditional herbal medicine use among hypertensives living in South African communities. BMC Complement Altern Med. 2013;13. doi:10.1186/1472-6882-13-38

16. Peltzer K, Pengpid S. The use of herbal medicines among chronic disease patients in Thailand: a cross-sectional survey. $J$ Multidiscip Healthc. 2019;12:573-582. doi:10.2147/JMDH.S212953

17. Ibrahim I, Hassali M, Saleem F, Al Tukmagi H. A qualitative insight on complementary and alternative medicines used by hypertensive patients. J Pharm Bioallied Sci. 2016;8(4):284. doi:10.4103/09757406.199349

18. Amira OC, Okubadejo NU. Frequency of complementary and alternative medicine utilization in hypertensive patients attending an urban tertiary care centre in Nigeria. BMC. 2007. https://bmccomple mentalternmed.biomedcentral.com/articles/10.1186/1472-6882-7-30.

19. Hughes GD, Aboyade OM, Beauclair R, Mbamalu ON, Puoane TR. Characterizing herbal medicine use for noncommunicable diseases in Urban South Africa. Evidence-Based Complement Altern Med. 2015;2015:1-10. doi:10.1155/2015/736074
20. Clement YN, Morton-Gittens J, Basdeo L, et al. Perceived efficacy of herbal remedies by users accessing primary healthcare in Trinidad. BMC Complement Altern Med. 2007;7:7. doi:10.1186/1472-6882-7-4

21. Picking D, Younger N, Mitchell S, Delgoda R. The prevalence of herbal medicine home use and concomitant use with pharmaceutical medicines in Jamaica. J Ethnopharmacol. 2011;137(1):305-311. doi:10.1016/j.jep.2011.05.025

22. Liwa A, Roediger R, Jaka H, et al. Herbal and alternative medicine use in tanzanian adults admitted with hypertension-related diseases: a mixed-methods study. Int J Hypertens. 2017;2017:1-9. doi:10.1155/ 2017/5692572

23. Diallo MST, Traore MS, Balde MA, et al. Prevalence, management and ethnobotanical investigation of hypertension in two Guinean urban districts. J Ethnopharmacol. 2019;231:73-79. doi:10.1016/j. jep.2018.07.028

24. Olisa NS, Oyelola FT. Evaluation of use of herbal medicines among ambulatory hypertensive patients attending a secondary health care facility in Nigeria. Int $J$ Pharm Pract. 2009;17(2):101-105. doi:10.1211/ijpp/17.02.0005

25. Tulunay M, Aypak C, Yikilkan H, Gorpelioglu S. Herbal medicine use among patients with chronic diseases. $J$ Intercult Ethnopharmacol.2015;4(3):217-220. doi:10.5455/jice.20150630 90040

26. Soner BC, Sahin AS, Sahin TK. A survey of Turkish hospital patients' use of herbal medicine. Eur J Integr Med. 2013;5(6):547552. doi:10.1016/j.eujim.2013.08.004

27. Erku DA. Prevalence and correlates of complementary and alternative medicine use among hypertensive patients in Gondar Town, Ethiopia. Evidence-Based Complement Altern Med. 2016;2016:1-7. doi:10.1155/2016/6987636

28. Singh V, Raidoo DM, Harries CS. The prevalence, patterns of usage and people's attitude towards complementary and alternative medicine (CAM) among the Indian community in Chatsworth, South Africa. BMC Complement Altern Med. 2004;4(1):1-7. doi:10.1186/ 1472-6882-4-3

29. Ried K, Fakler P. Potential of garlic (Allium sativum) in lowering high blood pressure: mechanisms of action and clinical relevance. Integr Blood Press Control. 2014;7:71. doi:10.2147/IBPC.S51434

30. Butterweck V, Derendorf H, Gaus W, Nahrstedt A, Schulz V, Unger M. Pharmacokinetic herb-drug interactions: are preventive screenings necessary and appropriate? Planta Med. 2004;70(9):784-791. doi: $10.1055 / \mathrm{s}-2004-827223$

31. Tarirai C, Viljoen AM, Hamman JH. Herb - drug pharmacokinetic interactions reviewed. Expert Opinion Drug Metabolism \&amp Toxicol. 2010;6:1515-1538. doi:10.1517/17425255.2010.529129

32. Izzo AA. Interactions between herbs and conventional drugs: overview of the clinical data. Med Principles Practice. 2012;21:404-428. doi: $10.1159 / 000334488$

33. Wang R, Zhang H, Sun S, Wang Y, Chai Y, Yuan Y. Effect of ginkgo leaf tablets on the pharmacokinetics of amlodipine in rats. Eur J Drug Metab Pharmacokinet. 2016;41(6):825-833. doi:10.1007/s13318015-0312-3

34. Osamor PE, Owumi BE. Complementary and alternative medicine in the management of hypertension in an urban Nigerian community. BMC Complement Altern Med. 2010;10(1):36. doi:10.1186/14726882-10-36

35. Salman SAB, Amrah S, Wahab MSA, et al. Modification of propranolol's bioavailability by Eurycoma longifolia water-based extract. $J$ Clin Pharm Ther. 2010;35(6):691-696. doi:10.1111/j.13652710.2009.01147.x

36. Nwokocha CR, Owu DU, McLaren M, et al. Possible mechanisms of action of the aqueous extract of Artocarpus altilis (breadfruit) leaves in producing hypotension in normotensive Sprague-Dawley rats. Pharm Biol. 2012;50(9):1096-1102. doi:10.3109/13880209.2 012.658113 
37. Nwokocha CR. Possible mechanism of action of the hypotensive effect of peperomia pellucida and interactions between human cytochrome P450 enzymes. Med Aromat Plants. 2012;01(04):1-5. doi:10.4172/2167-0412.1000105

38. Kim HR, Park SW, Cho HJ, et al. Comparative gene expression profiles of intestinal transporters in mice, rats and humans. Pharmacol Res. 2007;56(3):224-236. doi:10.1016/j.phrs.2007.06.005

39. Colalto C. Herbal interactions on absorption of drugs: mechanisms of action and clinical risk assessment. Pharmacol Res. 2010;62(3):207227. doi:10.1016/j.phrs.2010.04.001

40. Mansoor GA. Herbs and alternative therapies in the hypertension clinic. J Clin Anesth. 2001;7061(01):971-975. doi:10.1016/S08957061(01)02172-0
41. Dresser GK, Wacher V, Wong S, Wong HT, Bailey DG. Evaluation of peppermint oil and ascorbyl palmitate as inhibitors of cytochrome P4503A4 activity in vitro and in vivo. Clin Pharmacol Ther. 2002;72 (3):247-255. doi:10.1067/mcp.2002.126409

42. Teixeira K, Dos Santos P, Citadini ZV, DalBA S. Medicinal plants that can cause changes in blood pressure and interactions with antihypertensive agents. Am $J$ Ethnomedicine. 2017;04(01):1-8. doi: $10.21767 / 2348-9502.100002$

43. Lapenna S, Gemen R, Wollgast J, Worth A, Maragkoudakis P, Caldeira S. Assessing herbal products with health claims. Crit Rev Food Sci Nutr. 2015;55(13):1918-1928. doi:10.1080/ 10408398.2012 .726661
Journal of Multidisciplinary Healthcare

\section{Publish your work in this journal}

The Journal of Multidisciplinary Healthcare is an international, peerreviewed open-access journal that aims to represent and publish research in healthcare areas delivered by practitioners of different disciplines. This includes studies and reviews conducted by multidisciplinary teams as well as research which evaluates the results or conduct of such teams or healthcare processes in general. The journal

\section{Dovepress}

covers a very wide range of areas and welcomes submissions from practitioners at all levels, from all over the world. The manuscript management system is completely online and includes a very quick and fair peer-review system. Visit http://www.dovepress.com/testimonials. php to read real quotes from published authors. 